\title{
O MODELO META-STANDARD DE IMPLEMENTAÇÃO DA SUSTENTABILIDADE UTILIZADO PELA DIRETIVA EUROPEIA DE ENERGIA RENOVÁVEIS ${ }^{1}$
}

\author{
THE META-STANDARD IMPLEMENTATION MODEL FOR SUSTAINABILITY \\ USED BY THE EUROPEAN RENEWABLE ENERGY DIRECTIVE
}

Flavia Trentini ${ }^{2}$

\begin{abstract}
Resumo: O presente artigo tem por objetivo central analisar o modelo meta-standard de implementação da sustentabilidade utilizado pela Diretiva Europeia de Energia Renováveis $n^{\circ} 28 / 2009$. A metodologia utilizada para a pesquisa é a revisão teórica não sistematizada, que inclui a análise de textos normativos, livros e artigos sobre o tema. O estudo evidencia que a doutrina consagra a sustentabilidade numa tríplice vertente: ambiental, social e econômica. Com vistas ao desenvolvimento sustentável, a União Europeia utiliza uma ferramenta da nova governança: o modelo meta-standard. Esse modelo implica na inclusão de standards de sustentabilidade em um quadro normativo, com o intuito de definir os critérios essenciais para se considerar um biocombustível como sustentável, e levanta debates na literatura sobre seus prós e contras.
\end{abstract}

Palavras-chave: Sustentabilidade; Diretiva europeia 28/2009; Meta-standard; Biocombustíveis.

\begin{abstract}
The purpose of this article is to analyze the meta-standard model of sustainability implementation used by the European Renewable Energy Directive number 28/2009. The methodology was the non-systematized theoretical review, which includes the analysis of normative texts, books, and articles on the subject. The study points out that the doctrine establishes sustainability in a triple aspect: environmental, social and economic. Aiming sustainable development, the European Union uses a tool of the so-called new governance, the meta-standard model. This model implies the inclusion of sustainability standards in a normative framework, in order to define the essential criteria for considering a biofuel as sustainable, and raises doctrinal debates about its pros and cons.
\end{abstract}

Keywords: Sustainability; European Directive 28/2009; Meta-standard; Biofuels.

\section{INTRODUÇÃO}

Os conceitos de desenvolvimento sustentável e sustentabilidade são a base para a compreensão e definição da meta-standard de sustentabilidade para os biocombustíveis. Grande parte da recente atenção à sustentabilidade deriva da definição da Brundtland de desenvolvimento sustentável, a saber: "o desenvolvimento que satisfaz as necessidades do presente sem comprometer a capacidade das futuras gerações de satisfazerem as suas próprias necessidades”. Por sua vez, o conceito de produção sustentável que surgiu na Conferência das Nações Unidas sobre Meio Ambiente e

1 Artigo derivado da pesquisa "Certificação dos biocombustíveis e sustentabilidade: estudo sobre a coerência entre os sistemas comunitário europeu e brasileiro”, com fomento da Fapesp.

2 Professora Associada do Departamento de Direito Privado e de Processo Civil da Faculdade de Direito de Ribeirão Preto da Universidade de São Paulo (USP) e do Programa de Mestrado da mesma instituição. Possui doutorado em Direito pela Universidade de São Paulo, Pós-doutorado realizado na Scuola Superiore Sant'Anna di Studi Universitari e Perfezionamento (SSSUP) Pisa-Itália, com bolsa FAPESP e Pós-Doutorado em Administração/Economia das Organizações (FEA/USP). É Livre Docente em Direito Agrário pela FDRP-USP (2018). E-mail: trentini@usp.br 
Desenvolvimento, em 1992, está intimamente relacionado com o conceito de desenvolvimento sustentável (ONU: 1987; 1992).

O objetivo central deste artigo é analisar o modelo meta-standard de implementação da sustentabilidade utilizado pela Diretiva Europeia de Energias Renováveis (28/2009). Trata-se de uma revisão teórica que será realizada de maneira não sistematizada e contemplará textos normativos, livros e artigos sobre o tema.

O artigo se desenvolverá em quatro partes: a primeira analisará os aspectos gerais da sustentabilidade com relevo especial para suas três principais vertentes (ambiental, social e econômico). A segunda parte discutirá os standards de sustentabilidade principalmente no que diz respeito à sua inclusão em um quadro normativo e às implicações ao se tornarem obrigatórios. A terceira parte deter-se-á no estudo da diretiva europeia sobre energias renováveis em razão do desdobramento do conceito de sustentabilidade em seu texto. A última parte analisará o modelo meta-standard, utilizado pela diretiva 28/2009, para definir os critérios essenciais para se considerar um biocombustível como sustentável na União Europeia.

\section{ASPECTOS GERAIS DA SUSTENTABILIDADE}

A sustentabilidade ainda é um conceito vago, mas há um consenso crescente de que é necessário tentar defini-la para o desenvolvimento de ferramentas concretas no intuito de promover e medir as suas conquistas. Desde então, a sustentabilidade tem sido amplamente reconhecida por incluir dimensões sociais, econômicas e ambientais. As interpretações do conceito de "sustentabilidade" baseiam-se, minimamente, na abordagem desses três pilares.

Mas há quem ainda vá além. Realmente, dentre os vários autores que tratam das dimensões da sustentabilidade, destaca-se Ignacy Saches (2002; p.46) que, ao considerar o conceito dinâmico, em 1990 entendeu que possui cinco aspectos: social, econômico, ecológico, geográfico e cultural e, em 2002, acrescentou mais quatro: ambiental, territorial (no lugar de geográfico), político nacional e político internacional. Vale aqui o destaque para a conceituação que o autor estabelece de sustentabilidade ambiental como a que permite aos ecossistemas naturais realizarem autodepuração, e a ênfase dada à relação com as políticas internacionais, que teria como base o fortalecimento da ONU, controle do sistema financeiro internacional, verdadeira cooperação científica e diminuição das disparidades sociais entre os hemisférios norte e sul.

De volta aos três pilares, a dimensão ambiental pode ser entendida como a necessidade dos ecossistemas manterem sua capacidade de funcionamento por meio de mudanças ambientais e, se necessário, proporcionar a capacidade evolutiva (através da diversidade genética e de espécies) para formar estruturas e funções mais adequadas do ecossistema, à medida que as condições ambientais mudem (CABEZAS et al.: 2003; p. 168).

Por sua vez, os esforços para definir a sustentabilidade social cobrem um conjunto de componentes amplos e complexos, desde a ênfase da comunidade ao desenvolvimento e à redução da pobreza até a ênfase da comunidade internacional nos direitos humanos, trabalhistas e indígenas e a orientação da comunidade empresarial para a responsabilidade social (FAO, 2016; OIT, 2016) .

Portanto, a sustentabilidade social tem se concentrado em questões diversas como trabalho e direitos humanos, envolvimento e desenvolvimento da comunidade, desenvolvimento de tecno- 
logia e recursos humanos, preocupações do consumidor e responsabilidade do produto, o que gera muita dificuldade de se encontrar uma definição precisa de sustentabilidade social que seja abrangente e operacional. Neste sentido, Laura German e George Schoneveld (2012; p. 767), alertam que a tradução de princípios tão amplos de sustentabilidade social em um quadro normativo tem inevitavelmente levado à simplificação de responsabilidades para impactos sociais, muitas vezes complexos.

Finalmente, a sustentabilidade como objetivo à manutenção e à implementação do capital é denominada de sustentabilidade econômica, também muito indeterminada. A sustentabilidade econômica se concentra sobre as reservas naturais básicas que fornecem sua contribuição física, seja renovável ou não, aos processos de produção. Portanto, o interesse da sustentabilidade econômica é primariamente o processo produtivo, visto como um meio para verificar a relação existente entre os custos e os benefícios. Para um ato ser considerado sustentável, requer que os benefícios superem os custos, ou ao menos se igualem (VALERA: 2012; p. 45).

Segundo Gill e Meppen (1998; p. 123), é possível interpretar o conceito de sustentabilidade como um estado econômico em que as exigências feitas ao ambiente por parte da população e do setor empresarial poderiam ser satisfeitas sem reduzir a capacidade de manutenção do ambiente para as futuras gerações. Porém, alerta Eero Palmujoki (2009; p. 149), existem diferenças na ênfase da sustentabilidade econômica entre países desenvolvidos e em desenvolvimento, organizações não governamentais e organizações internacionais. A principal distinção centra-se nos conceitos de rentabilidade econômica/viabilidade, referindo-se, por um lado, à economia de mercado e, por outro, às possibilidades das comunidades locais no desenvolvimento econômico.

Dessa forma, o conteúdo dos critérios de sustentabilidade deve estar ligado à compreensão do que é desenvolvimento sustentável e sustentabilidade. Os standards de sustentabilidade são aplicados para avaliar oportunidades e riscos decorrentes das dimensões econômica, ambiental e social. Por exemplo, os critérios de sustentabilidade de caráter ambiental constituem exigências impostas aos fornecedores com vista a reduzir o uso de recursos naturais e a minimizar os riscos ambientais.

\section{STANDARDS DE SUSTENTABILIDADE}

O comércio globalizado também responde às demandas do desenvolvimento sustentável, exigindo o uso de critérios de sustentabilidade para os produtos comercializados internacionalmente. A existência de critérios de sustentabilidade visa a garantir a sustentabilidade a longo prazo e a assegurar investimentos. Outro efeito positivo da introdução de standard de sustentabilidade é que os produtos que os cumprem podem ser posteriormente beneficiados com subsídios governamentais (PAVLOVSKAIA: 2014; p. 21).

Dessa forma, ensina Evgenia Pavlovskaia (2014; p. 21) que os standards de sustentabilidade podem ser incluídos em um quadro normativo com a possibilidade de se tornarem obrigatórios. Mas também podem fazer parte de uma certificação de qualidade voluntária (privada ou pública), como as definidas pela diretiva 28/2009. Os quadros com standards de sustentabilidade, principalmente de caráter voluntário, ou seja, não obrigatório, foram iniciados por agentes privados. Os denominados sistemas de certificação voluntários existem em diferentes ramos, como biocombus- 
tíveis, silvicultura, café e algodão, e servem a diversos fins. A maioria dos quadros com standards de sustentabilidade tem uma estrutura hierárquica, na qual o principal objetivo do quadro é transformado em uma série de subprincípios.

Por sua vez, o desenvolvimento de um quadro jurídico ou de um padrão de sustentabilidade com standards deve incluir uma estrutura organizacional e um conjunto mínimo de itens. Um quadro normativo com standards de sustentabilidade deve estar relacionado com seus mecanismos de controle, por exemplo (PAVLOVSKAIA: 2013; p. 76).

O tema também pode ser problematizado a partir da seguinte questão: é necessário usar critérios de sustentabilidade em estruturas normativas? Evgenia Pavlovskaia (2013; p. 76) considera que os standards de sustentabilidade em um quadro normativo possuem o potencial de estabelecer uma proteção ambiental mais profunda e cientificamente fundamentada; oferecem medidas de controle e avaliação mais eficazes; oferecem oportunidades mais seguras para o planejamento futuro e também promovem e protegem investimentos. Por outro lado, alerta que os critérios de sustentabilidade nos quadros normativos são menos flexíveis às mudanças tecnológicas e de mercado e podem ser uma alternativa cara. A diferença de implementação e de abordagem entre os atores envolvidos e o desenvolvimento de quadros normativos de sobreposição fraca podem também servir de empecilho sua boa aplicação. Conclui a autora que esses argumentos devem ser considerados para se escolher qual a forma mais apropriada de utilizar critérios de sustentabilidade.

Portanto, é importante que, uma vez inseridos os standards de sustentabilidade nos quadros normativos, esses sejam revisados e avaliados principalmente sobre seus padrões e metas. Um mecanismo relevante no controle para o cumprimento dos critérios de sustentabilidade pode ser a obrigação de os atores envolvidos elaborarem relatórios e auditorias. Porém, a elaboração do relatório deve ser prevista nos textos normativos, bem como as questões devem ser abordadas por esse (PAVLOVSKAIA: 2013; p. 76).

\section{A DIRETIVA EUROPEIA SOBRE ENERGIAS RENOVÁVEIS}

A diretiva 28/2009 é um exemplo de iniciativa normativa internacionalmente importante, visto que os critérios de sustentabilidade estabelecidos criam uma ligação entre sustentabilidade e sua implementação prática em uma cadeia produtiva (PAVLOVSKAIA: 2014; p. 10). Por outro lado, Stavros Afionis e Lindsay Stringer (2012; p. 115), apesar de considerarem a política de biocombustíveis europeia o maior exemplo de difusão e desdobramento do conceito de desenvolvimento sustentável em um texto normativo, alertam para o fato de que a ambição da UE seria considerá-la uma "normative power" internacional sobre o tema.

Sublinha-se que, após a entrada em vigor da diretiva 28/2009, a política comunitária energética deixa de possuir caráter meramente programático e passa a ser vinculante, incidindo diretamente e de modo obrigatório sobre a esfera de ação dos Estados-Membros. Essa alteração é muito significativa e demonstra a importância das instituições comunitárias no setor. A diretiva mencionada, para Jolene Lin (2011; p. 36), introduz o mais abrangente e avançado sistema de sustentabilidade já visto em textos normativos. Os critérios de sustentabilidade para os biocombustíveis são estabelecidos e aplicam-se tanto aos biocombustíveis produzidos no mercado interno como aos importados. 
A diretiva 28/2009 disciplina toda a matéria de energias renováveis sobre eletricidade, biocombustíveis e também dos setores de calefação e resfriamento. O objetivo de unir todas as matérias referentes à energia foi simplificar e garantir maior certeza jurídica ao setor energético (UE; 2009).

$\mathrm{O}$ artigo $3^{\circ}$ da diretiva estabelece que cada EstadoMembro deve assegurar que a quota de energia de fontes renováveis seja de ao menos $20 \%$ do consumo final bruto de energia em 2020. Outra meta fixada pela diretiva foi a de energia renovável no setor de transportes, ou seja, em 2020 os Estados-Membros devem atingir a quota de uso de 10\% de energias renováveis no setor (UE; 2009).

Susanna Quadri (2011; p. 845) considera que, para se alcançar o duplo objetivo da segurança de abastecimento e da redução das emissões de gases nocivos ao ambiente, a consolidação do quadro normativo da UE representou um impulso relevante para a adoção de medidas nacionais destinadas ao aumento da produção e do uso de energias renováveis.

Portanto, a diretiva 28/2009, diferentemente dos textos normativos anteriores, desenha uma ligação explícita entre o consumo de biocombustíveis e sua produção sustentável. Stavros Afionis e Lindsay Stringer (2012; p. 115) consideram que a preocupação pública com os potenciais impactos negativos, juntamente com as generalizadas críticas de ONGs, obrigaram o desenvolvimento de normas comunitárias e critérios para garantir uma indústria de biocombustíveis sustentável.

Apesar de a diretiva impor objetivos vinculantes aos Estados-Membros, é bastante flexível no que diz respeito à escolha do mix energético, ou seja, cada Estado é livre para escolher a tecnologia e os instrumentos para atingir o objetivo. Porém, no setor de transporte, essa flexibilidade não é verificada, visto que a quota de $10 \%$ de energia renovável manteve-se fixa no setor até 2020 (UE, 2009).

Susanna Quadri (2011; p. 851) aponta algumas motivações para ausência de flexibilidade no setor de transportes. Em primeiro lugar, porque os biocombustíveis contribuem para atenuar a dependência da UE do petróleo. Em segundo lugar, porque no setor de transporte se registra uma maior emissão de gases nocivos do que em outros setores da economia. Ressalta-se que não se podem incluir na conta para atingir a meta de $10 \%$ os biocombustíveis considerados não sustentáveis, ou seja, que não atingem os critérios especificados pela normativa.

Portanto, é necessário respeitar os critérios de sustentabilidade para que o biocombustível em questão possa contar nas obrigações comunitárias ou nacionais em matéria de energias renováveis ou para ser elegível para apoio financeiro ou auxílio estatal. Uma vez que os critérios de sustentabilidade foram adotados nos termos do artigo 95 do Tratado que institui a Comunidade Europeia (TCE), os Estados-Membros não estão autorizados a adotar critérios adicionais ou a excluir os biocombustíveis por razões de sustentabilidade que não as enunciadas na diretiva relativa às energias renováveis. Cabe lembrar que o cumprimento destes critérios não é uma condição prévia para a colocação dos biocombustíveis no mercado da UE, os biocombustíveis podem ser importados mesmo que os critérios não sejam cumpridos, mas não contarão nas metas comunitárias ou nacionais em matéria de energias renováveis e não são elegíveis para apoio financeiro ou auxílio estatal.

As considerações iniciais da primeira proposta da Comissão já alertavam que, apesar dos artigos 15, 16 e 17 imporem obrigações vinculantes aos Estados-Membros no que se refere à sus- 
tentabilidade dos biocombustíveis e biolíquidos, era vetado também aos Estados-Membros adotarem medidas que criassem obstáculos ao comércio de biocombustiveís e matérias-primas (UE; 2008). Portanto, estes artigos não incentivam aos Estados-Membros a prosseguir com iniciativas que visem a propor critérios de sustentabilidade adicionais nos Estados-Membros (EICKHOUT et al.: 2008; p. 22).

Os critérios de sustentabilidade estão no centro do debate sobre políticas de biocombustíveis desde que o marco regulatório foi introduzido, em 2009, porque relaciona-se diretamente com a segurança e a competitividade do mercado. Interessante recordar que o principal documento antecessor da normativa 28/2009 foi o Livro Verde de 2006 da Comissão sobre a energia, a estratégia energética da Europa, o qual se baseava em três princípios fundamentais: a segurança (disponibilidade de abastecimento), a competitividade (referente à acessibilidade dos preços) e a sustentabilidade (dimensão ambiental) (UE; 2006). Um elemento importante desta abordagem foi a excessiva dependência da Europa ao petróleo e ao gás importados e o desenvolvimento de uma análise coerente, com base nos impactos econômicos, ambientais e sociais dos biocombustíveis.

Em relação aos países em desenvolvimento, o documento da UE considerava que seria necessário desenvolver políticas e estratégias para os biocombustíveis, tendo em conta as potencialidades nacionais dos países-membros da UE e terceiros, as perspectivas de mercado nacionais, regionais e internacionais, as normas técnicas, as infraestruturas e outros aspectos econômicos, sociais e ambientais (UE; 2006).

Cabe lembrar também que o cumprimento dos critérios de sustentabilidade não é um pré-requisito absoluto para a introdução de biocombustíveis no mercado europeu, mas aqueles que não satisfazem os critérios são considerados combustíveis fósseis. Como tal, os critérios de sustentabilidade são um conjunto de critérios normativos que asseguram a sustentabilidade dos biocombustíveis por meio de reduções verificadas das emissões de GEE em comparação com os combustíveis fósseis e através da extração e utilização sustentáveis de matérias-primas na produção de biocombustíveis.

A regra central sobre os critérios de sustentabilidade dos biocombustíveis encontra-se nos artigos 17, 18 e 19 da diretiva 28/2009. O artigo 17 é constituído por nove parágrafos e refere-se ao conteúdo material dos critérios de sustentabilidade estabelecidos por lei ${ }^{3}$. O artigo 18 estabelece os requisitos para controlar o cumprimento dos critérios de sustentabilidade. Já o artigo 19 explica a metodologia para o cálculo dos impactos de GEE dos biocombustíveis. A lista dos critérios de sustentabilidade para biocombustíveis da diretiva 28/2009 é praticamente repetida na diretiva 30/2009. Os critérios constantes da diretiva 28/2009 aplicam-se aos biocombustíveis líquidos e

3 Nos Estados Unidos, a regulação está apenas começando a abordar os padrões de sustentabilidade. A Lei de Independência e Segurança Energética dos Estados Unidos (EISA, na sigla em inglês) exige que a Agência de Proteção Ambiental (EPA) desenvolva regulamentações sobre a pegada de carbono dos biocombustíveis e analise os critérios do Renewable Fuel Standard (RFS) e relate outras questões de sustentabilidade abrangentes. A EPA recentemente elaborou um projeto de regulamento de implementação no qual faz menção sobre como os sistemas de certificação podem auxiliar na verificação e rastreamento de "biomassa sustentável". O projeto de regulamentação também busca soluções para os impactos da água, do ar e do solo associados ao aumento da produção de biocombustíveis. No entanto, o projeto de regulamentação não adota uma abordagem meta-normalizada. Detalhadamente sobre o assunto veja Endres (2010). 
gasosos e também aos biolíquidos utilizados para outros fins energéticos que não o de transporte (UE: 2009).

O número 3 do artigo 17 exige que os biocombustíveis não sejam produzidos a partir de matérias-primas obtidas de terrenos com elevado valor de biodiversidade (por exemplo, floresta primária) ou de terrenos com elevado teor de carbono (por exemplo, zonas úmidas ou turfeiras). $\mathrm{O}$ número 6 do artigo 17 exige que certas práticas agroambientais sejam seguidas no respectivo cultivo de biomassa. Além disso, o artigo 17 prevê que os critérios se apliquem independentemente de as matérias-primas serem cultivadas dentro ou fora do território da UE; assim, os critérios também têm uma dimensão externa à UE. As reduções líquidas de GEE provenientes dos biocombustíveis são calculadas de acordo com a metodologia estabelecida no artigo 19 e detalhadas no anexo V da diretiva relativa às energias renováveis.

Para Stefano Ponte (2014; p. 3), a regulamentação, no caso dos biocombustíveis, desempenhou uma função na formação de um campo-base para sustentabilidade, mas com um foco principal na redução das emissões de GEE, em vez de impactos ambientais e sociais mais amplos, elevando-os a requisitos globais para a sustentabilidade dos biocombustíveis.

Verifica-se que os critérios de sustentabilidade inseridos na diretiva não refletem traços e características especiais regionais, tais como variações climáticas, qualidade do solo, infraestruturas e desenvolvimento econômico. A ausência da menção regional pode resultar em dificuldades na implementação dos critérios de sustentabilidade e na avaliação de seu cumprimento.

Salienta-se que os Estados-Membros não podem ter critérios de sustentabilidade mais baixos do que os estabelecidos pela UE e devem aceitar todos os elencados na diretiva 28/2009 pela UE (USDA: 2016). Utilizar os padrões de sustentabilidade voluntária existentes é conveniente e estável sob circunstâncias de mudanças constantes, devido à sua capacidade de incorporar vários padrões de sustentabilidade. Também é relativamente fácil de ser atualizado, porque o sistema inteiro não precisa mudar, mas apenas seus componentes separados. Esta abordagem ajuda a acompanhar o rápido desenvolvimento global do setor dos biocombustíveis. Convém analisar se questões tão amplas e complexas, como o cumprimento de critérios de sustentabilidade sob diferentes condições técnicas, geográficas e jurídicas, devam ser regulamentadas (PAVLOVSKAIA: 2014; p. 105).

Evgenia Pavlovskaia (2014; p. 22) justifica a inexistência de detalhamento dos critérios de sustentabilidade devido ao fato de que esses poderiam ser considerados pela OMC como medidas causadoras de distorção no comércio mundial. Então a UE optou por meramente inclui-los nos requisitos de informação e monitoramento dos Estados-Membros e também por considerar duvidoso que listas longas possam ser incorporadas com êxito num quadro jurídico (NAIKI: 2016; p. 144).

No que tange ao desafio de grandes listas, sugerem-se alguns métodos: a primeira opção é dividir uma lista longa em um número menor de categorias ou problemas principais. Podem ser incluídos em um texto normativo com uma explicação sobre qual a qualidade ambiental que deve ser adquirida dentro de cada categoria. Posteriormente, critérios de sustentabilidade mais detalhados dentro de cada categoria podem ser elaborados e anexados ao corpo principal de um quadro normativo (PAVLOVSKAIA: 2013; p. 76). 
O sistema de sustentabilidade dos biocombustíveis da UE inclui também requisitos de monitoramento e de relatório ${ }^{4}$. Os Estados-Membros da UE, por exemplo, devem apresentar um relatório sobre o impacto dos biocombustíveis e biolíquidos na biodiversidade, nos recursos hídricos, na qualidade da água, na qualidade do solo, na redução de emissões de GEE, nas mudanças nos preços das commodities e no uso da terra associadas ao aumento do uso da biomassa. Embora não existam critérios obrigatórios de sustentabilidade social, a Comissão Europeia deve informar sobre o impacto dos biocombustíveis nos aspectos sociais e sobre o impacto na disponibilidade de alimentos a preços acessíveis. A Comissão também pretende acompanhar a origem dos biocombustíveis consumidos na UE e os impactos da sua produção na UE e em países terceiros, a utilização dos solos e a alteração da utilização dos solos, os preços das matérias-primas e a segurança alimentar (UE, 2009).

Ainda sobre a importância da fixação de critérios de sustentabilidade para os bicombustíveis, Stavros Afionis e Lindsay Stringer (2012; p. 1) alertam que o interesse europeu na sustentabilidade ambiental e social deve ser analisado em conjugação com outros objetivos políticos, como a competitividade econômica e comercial. Continuam os autores afirmando que a Europa aspira a ser uma líder na governança ambiental global, mas nunca se deve perder de vista que ela representa o maior bloco comercial do mundo, responsável por um quinto do comércio mundial.

Uma abordagem duradoura e eficaz para assegurar a utilização sustentável da biomassa como um todo para fins energéticos está em plena discussão nas instituições da UE, que deverá modificar vários pontos da política climática e energética para 2030 e para além desse ano. Alguns pontos estão nas metas da UE, dentre eles: a) melhoria da informação e colheita de dados; b) objetivos específicos e claros para setores; c) e o melhoramento dos critérios de sustentabilidade. A elaboração de um novo quadro normativo facilitará a implementação de uma política de energias renováveis sustentáveis e estas questões estão sendo ativamente discutidas pela UE no setor de bioenergia. Para a UE também é uma prioridade clara a criação de um clima de investimento estável. Contudo, o estudo de Allen et al. (2016; p. 12) alerta que o quadro político para as energias renováveis precisa ser elaborado também em outros níveis, visto que muitas decisões são tomadas nos âmbitos global, regional e local.

\section{O MODELO META-STANDARD DE SUSTENTABILIDADE DOS BIOCOMBUSTÍVEIS}

A União Europeia (UE) sem dúvida é o ator internacional ativo na promoção do desenvolvimento de biocombustíveis sustentáveis e, com a diretiva 28/2009, introduziu um regime de sustentabilidade que torna a certificação de qualidade obrigatória aos biocombustíveis elegíveis para

4 O objetivo do relatório é avaliar os progressos realizados pelos Estados-Membros na promoção e utilização das energias renováveis ao longo da trajetória para os objetivos de 2020 e apresentar um relatório sobre a sustentabilidade dos biocombustíveis e biolíquidos consumidos na UE e os impactos deste consumo. As avaliações têm se baseado nos dados do Eurostat sobre as energias renováveis, nos relatórios sobre os progressos dos Estados-Membros no domínio das energias renováveis apresentados à Comissão, nas próprias investigações da Comissão e na investigação requerida pela Comissão Renewable Energy Progress and Biofuels Sustainability (ECOFYS: 2014 e 2016; UE: 2013 e 2015). 
apoio financeiro e cumprimento de metas. Para a inclusão da sustentabilidade no texto normativo, a UE se utiliza do modelo meta-standard. Trata-se de uma fórmula inovadora no conjunto de ferramentas de nova governança ambiental.

Segundo Jolene Lin (2011; p. 34) e Dehue et al. (2007; p. 6), o conceito de meta-standard é fundamental para entender a normativa europeia de energias renováveis que inclui regras sobre a sustentabilidade dos biocombustíveis. O artigo 17 e seguintes da diretiva 28/2009, por meio de meta-standard, define os critérios essenciais para considerar um bicombustível sustentável. Neste modelo, o cumprimento da meta-standard é atestado por uma certificação de qualidade, que verifica se os requisitos da meta-standard foram cumpridos na prática. Os requisitos presentes na certificação devem ser confrontados com a meta-standard e por isso é de suma importância que essa tenha procedimentos de auditoria e verificação. Jolene Lin esclarece a definição com o seguinte exemplo: se uma certificação voluntária, como o Greenergy para a cana-de-açúcar brasileira, atender a todos os critérios de sustentabilidade da UE (a meta-standard), será considerada um padrão de certificação. Um operador econômico que esteja de acordo com a norma Greenergy pode utilizar essa certificação para demonstrar a conformidade com os critérios de sustentabilidade da UE.

Alguns pontos positivos são elencados para o uso do modelo meta-standard. O primeiro deles é que muitos critérios para promover a sustentabilidade e práticas de produção de matéria-prima já existem e foram desenvolvidos por organizações da sociedade civil. O uso de uma meta-standard evita essencialmente "reinventar a roda". Isso leva ao segundo benefício, que é a economia de tempo e custos, visto que o desenvolvimento de um padrão de sustentabilidade por meio de um processo de regulação multi-stakeholder pode levar vários anos e é muito caro. O terceiro benefício encontra-se na nova perspectiva de governança global, a meta-standard da UE poderá contribuir para o processo de simplificação dos sistemas de certificação e de harmonização das normas mundiais, o que reduzirá os custos de transação para os produtores de biocombustíveis e promoverá o crescimento de uma indústria sustentável de biocombustíveis (LIN: 2011; p. 36; DEHUE et al.: 2007; p. 6; PAVLOVSKAIA: 2014; p. 103; NAIKI: 2016; p.148). Também conta como um aspecto positivo o fato da existência de uma série de iniciativas de certificações voluntárias poder levar a uma concorrência benéfica, resultando em melhorias nas normas e implementações e ferramentas de verificação (SCARLAT; DALLEMAND: 2011; p. 1644).

Nesse mesmo sentido, Evgenia Pavlovkaia (2014; p.103) acrescenta a função de harmonização da meta-standard, afirmando que padrões de sustentabilidade voluntários escolhidos podem promover mercados regionais e internacionais e, dessa maneira, também podem contribuir para a qualidade dos mecanismos de controle utilizados. O uso da meta-standard também apresenta o potencial de desenvolver uma lista mais funcional de critérios de sustentabilidade para biocombustíveis através da coleta de conhecimento técnico crescente dos requisitos alternativos de sustentabilidade. Este método pode igualmente encorajar a UE ao estabelecimento de novas normas de sustentabilidade melhor definidas.

No entanto, existem também dúvidas sobre se a difusão da meta-standard da UE através de certificações privadas, na prática, aumenta as possibilidades de "harmonização" dos critérios de sustentabilidade dos biocombustíveis em todo o mundo ou de "alguma consolidação do mercado de normas voluntárias". Sobre isso, afirma Yoshiko Naiki (2016; p. 144): "De fato, o sistema de aprovação da Comissão Europeia aumentou a concorrência (e não necessariamente a harmonização)". 
Por outro lado o uso de meta-standard pode ser visto de forma negativa, pois pode ser considerado uma forma disfarçada de discriminação comercial, além de seus custo para os pequenos produtores (LIN: 2011; p. 36; DEHUE et al.: 2007; p. 6; PAVLOVSKAIA: 2014; p. 104; WESTBERG; JOHNSON: 2013; p. 3). Zarilli (2010; p. 93) observa os custos dos sistemas de certificação de qualidade para pequenos produtores de países em desenvolvimento e acrescenta que subsistem preocupações quanto à capacidade dos países em desenvolvimento de participarem efetivamente no processo de criação das normas e do risco de grandes produtores nacionais desempenharem um papel desproporcionalmente influente no estabelecimento de requisitos de sustentabilidade.

Outro aspecto negativo levantado é que para satisfazer os critérios de sustentabilidade seriam necessários recursos administrativos capazes de reunir, medir e monitorar dados, o que implicaria em custos. Considera-se, então, que em razão dos encargos administrativos (mecanismos de controle), a adoção de critérios de sustentabilidade pelo modelo meta-standard favoreceria intrinsecamente a produção em larga escala em relação a instalações de produção menores, a menos que fossem implementados controles adicionais (WESTBERG; JOHNSON: 2013; p. 3; SCARLAT; DALLEMAND: 2011; p. 1644).

A abordagem meta-standard também comporta o risco de proliferação de indicadores diferentes, o que prejudicaria a ideia de racionalizar os esforços de certificação. Um padrão genérico de indicadores globais poderia contornar os problemas oriundos da proliferação de sistemas de certificação (SCARLAT; DALLEMAND, 2011, p. 1645).

De acordo com o exposto, a existência de uma meta-standard sobre os critérios de sustentabilidade é administrativamente eficiente para a UE, mas é considerada problemática para as relações externas, porque os países terceiros poderiam vê-la como uma imposição da UE de um padrão externo. Outro desincentivo ao uso da meta-standard é a falta de flexibilidade e customização. Neste caso, Johan Westberg e Francis Johnson (2013; p. 33) afirmam a importância dos acordos bilaterais, pois esses seriam um mecanismo que compensaria a rigidez de uma meta-standard com as oportunidades de adequações derivadas de um acordo negociado diretamente, particularmente com aqueles que são mais afetados pela rigidez da norma. Assim, uma vantagem principal da abordagem bilateral é que ela não necessariamente precisa suplantar ou enfraquecer uma meta-standard, mas pode servir para equilibrá-la e fornecer um tipo mais sensível de direção, país por país.

Muitas das dificuldades apontadas não resultam da utilização da meta-standard per se, mas sim da incapacidade de monitoramento dos sistemas voluntários de certificação e pluralidade e inconsistência de alguns sistemas nacionais de certificação. Assim, esse modelo, baseado em meta-standard, pode ser muito eficiente, visto que se baseia em padrões existentes, mas, por outro lado, suscita várias dúvidas sobre a eficiência dos sistemas privados de certificação e sobre a sua capacidade de garantir que os critérios foram respeitados ao longo da cadeia (LIN: 2011; p. 38; PELSY: 2008; p. 131). Inclusive, para Jolene Lin (LIN: 2011; p.38), o objetivo de 10\% de biocombustíveis deveria ser suspenso até que exista uma compreensão mais clara dos impactos da produção de biocombustíveis. Outro problema apontado pelo estudo de Bart Dehue et al. é o fato de não abordarem os chamados macroefeitos, como efeitos de meta-standard de deslocamento e competição com os alimentos. Portanto, também deve ser complementado por mecanismos eficazes para prevenir esses macroefeitos indesejados (DEHUE et al.: 2007; p. 6). 
A diretiva 28/2009 especifica que os operadores econômicos ${ }^{5}$ dispõem de três métodos de verificação dos critérios de sustentabilidade. Em primeiro lugar, é obrigatório que todos os EstadosMembros criem um sistema nacional de certificação que implemente os requisitos estabelecidos na diretiva. Em segundo lugar, os operadores econômicos podem demonstrar a sua conformidade utilizando um regime (privado) voluntário reconhecido pela Comissão. Em terceiro lugar, podem utilizar acordos bilaterais ou multilaterais com países terceiros, contendo disposições sobre critérios de sustentabilidade que correspondam aos da diretiva (UE, 2009). Existe ainda uma quarta opção não explorada pela teoria e nem pela prática, mas presente na Comunicação da Comissão de 2010, que prevê a possibilidade que esta avalie e reconheça regimes voluntários atípicos, que podem assumir várias formas, como mapas que indicam a conformidade ou não de certas zonas geográficas com os critérios, ferramentas de cálculo para avaliar a poupança de gases de efeito estufa ou ainda valores desses gases associados a uma dada matéria-prima na agricultura regional. Não existe um procedimento estabelecido previamente e a Comissão irá defini-lo quando receber um pedido de reconhecimento deles (UE: 2010).

Os regimes de certificação voluntários nacionais são sistemas de controle que verificam a sustentabilidade dos biocombustíveis. Os sistemas nacionais podem variar consideravelmente entre os Estados-Membros. Por sua vez, os regimes de certificação voluntária possuem, em regra, carácter privado e reúnem agricultores, empresas, organizações não governamentais (ONGs), peritos, governos e agências intergovernamentais interessados em assegurar a sustentabilidade da produção e transformação de biocombustíveis (ROMPPANEN: 2013; p. 343).

Os acordos internacionais e os regimes voluntários têm uma grande vantagem em relação aos sistemas dos Estados-Membros: seus certificados de qualidade são automática e obrigatoriamente reconhecidos em toda a União, garantindo assim elegibilidade para a contribuição para os objetivos energéticos e para as medidas de auxílio estatal (NASTASI: 2013; p. 3).

Por outro lado, os sistemas nacionais podem se adaptar melhor às circunstâncias locais, especialmente nos Estados-Membros com a produção doméstica de biocombustíveis. É provável que a escolha seja tomada com base em questões como a própria produção de biocombustíveis e o

\footnotetext{
5 Segundo Evgenia Pavlovskaia (2013, p. 96), “o conceito de 'operadores econômicos' não está claramente definido na diretiva 28/2009 da UE, e exige mais explicações. Podem ser numerosos os grupos de agentes que podem funcionar como operadores econômicos e podem estar envolvidos nos mecanismos de controle previstos no artigo 18. Estes grupos devem ser especificados mais claramente. Possivelmente, o termo 'operadores econômicos' pode incluir atores que criam e trabalham em marcos juridicamente vinculativos de padrões voluntários de sustentabilidade para biocombustíveis. Os operadores econômicos podem ser demandados por diferentes mecanismos de controle, desde que trabalhem sob diferentes circunstâncias e condições. Como exemplo, pode haver diferença nas abordagens de controle e mecanismos para uma empresa multinacional e um pequeno agricultor local em um país em desenvolvimento. Existem também diferentes possibilidades de utilização do sistema de balanço de massas. A diretiva 28/2009 não traz a definição de operador econômico em seu artigo $1^{\circ}$. O Tribunal de Contas da UE assim definiu operador econômico: empresa que produz e/ou comercializa biomassa ou biocombustíveis. Os operadores econômicos têm de demonstrar que cumprem os requisitos de sustentabilidade, podendo fazê-lo em conformidade com um sistema nacional ou recorrendo a regimes voluntários. Os operadores econômicos fazem parte da cadeia de aprovisionamento de biocombustíveis" (TRIBUNAL DE CONTAS EUROPEU: 2016).
} 
mercado atuante, o que pode inevitavelmente levantar preocupações quanto à coerência global do quadro geral de implementação (ROMPPANEM: 2015; p. 120).

\section{CONCLUSÃO}

Verifica-se que o conceito de sustentabilidade não é unívoco na literatura, porém pode-se afirmar que a sua tríplice vertente: ambiental, social e econômica está consagrada. A UE na diretiva sobre biocombustíveis utiliza o modelo meta-standard, inovador no conjunto de ferramentas da nova governança. Trata-se de standards de sustentabilidade que servem de referência para as certificadoras (públicas ou privadas), o que torna as políticas nacionais ou internacionais dependentes dessas.

Assim, esse modelo, baseado em meta-standard, pode ser muito eficiente, visto que se baseia em padrões existentes. Ademais, esse modelo gera economia de tempo e custos, visto que permite o desenvolvimento de um padrão de sustentabilidade por meio de um processo de regulação multi-stakeholder e de harmonização das normas mundiais. Entende-se, ainda, que a inclusão de standards de sustentabilidade em um quadro normativo possui inclusive o potencial de estabelecer uma proteção ambiental mais profunda e cientificamente fundamentada.

Porém, admite-se que o modelo meta-standard ainda deva ser aperfeiçoado para que não gere discriminação comercial entre os países produtores de biocombustíveis. Deve-se também buscar alternativas que possibilitem a participação aos pequenos produtores de países em desenvolvimento no processo de criação dos standards para sustentabilidade

Por fim, ressaltou-se que a empresa que produz ou comercializa biocombustíveis pode demonstrar sua conformidade com a meta-standard de três maneiras: por um sistema nacional, por uma certificação voluntária reconhecida pela Comissão ou por acordos bilaterais e multilaterais. A pluralidade de sistemas é prejudicial, visto que os agentes procurarão aquelas em que os controles se apresentem mais fluídos e com menores custos, em detrimento da sustentabilidade almejada.

$\mathrm{O}$ setor de transporte apresenta altos índices de emissão de gases nocivos em relação a outros setores da economia, por isso verifica-se a importância da incorporação dos biocombustíveis. Ressalta-se, por outro lado, que uma produção de biocombustíveis sem standards mínimos de sustentabilidade pode contribuir para a (in)sustentabilidade climática global, desgastando uma das principais vantagens na adesão desses combustíveis alternativos.

Os critérios estabelecidos pela diretiva refletem em boa parte textos internacionais ambientais e sociais como: espaços protegidos, áreas ricas em biodiversidade e convenções da OIT. Desta forma, colabora na formação de um campo-base para sustentabilidade, e eleva os standards como requisitos globais para a sustentabilidade dos biocombustíveis.

\section{REFERÊNCIAS}

AFIONIS, Stavros; STRINGER, Lindsay C. European Union leadership in biofuels regulation: Europe as a normative power? Journal of Cleaner Production. v.32, p. 114-123, 2012.

ALLEN, Ben; BALDOCK, David; NANNI, Silvia; BOWYER, Catherine. Sustainability criteria for biofuels made from land and non-land based feedstocks. Londres: Institute for European Environmental Policy, 
O modelo meta-standard de implementação da sustentabilidade utilizado pela diretiva europeia...

TRENTINI, F.

2016. Disponível em: https://ieep.eu/uploads/articles/attachments/cc72ca6f-7361-4e9b-b208-c90e8308c98/ ieep 2016 sustainability criteria for biofuels post_2020.pdf? v=6366450995. Acesso em: 16 ago. 2017.

CABEZAS, Heriberto et all. Sustainability: ecological, social, economic, technological, and systems perspectives. Clean Technologies and Environmental Policy, v. 5, n. 3-4, p. 167-180, 2003.

DEHUE, Bart; MEYER, Sebastian; HAMELINCK, Carlo. Towards a harmonised sustainable biomass certification scheme. Utrecht: Ecofys, 2007.

ECOFYS. Renewable energy progress and biofuels sustentability. Utrecht: Ecofys, 2014.

ECOFYS. Methodologies for the identification and certification of Low ILUC risk biofuels. União Europeia: Ecofys, 2016.

EICKHOUT, B.; BORN, G. J. van den; NOTENBOOM, J.; OORSCHOT, M. van; ROS, J. P. M.; VUUREN, D. P. van; WESTHOEK, H. J. Local and global consequences of the EU renewable directive for biofuels: testing the sustainability criteria. Bruxelas: MNP Report, 2008.

ENDRES, Jody M. Clearing the air: the meta-standard approach to ensuring biofuels environmental and social sustainability. Virginia Environmental Law Journal. v. 28, n. 1, p. 73-120, 2010.

FAO. Organização das Nações Unidas para a Alimentação e a Agricultura, 2016. Disponível em: http:// www.fao.org/brasil/pt/. Acesso em: 16 ago. 2017.

GERMAN, Laura; SCHONEVELD, George. A review of social sustainability considerations among EUapproved voluntary schemes for biofuels, with implications for rural livelihoods. Energy Policy, n, 51, p. 765-778, 2012.

LIN, Jolene S.W. The Environmental Regulation of Biofuels: Limits of the Meta-Standard Approach. Carbon \& Climate Law Review, v.5, n.1, p. 34-43, 2011.

MEPPEM, Tony; GILL, Roderic. Planning for sustainability as a learning concept. Ecological Economics, Elsevier, v. 26, p. 121-137, 1998.

NAIKI, Yoshiko. Trade and Bioenergy: Explaining and Assessing the Regime Complex for Sustainable Bioenergy. The European Journal of International Law, v. 27, n. 1, p. 129-159. 2016.

NASTASI, Giuseppe. Achieving credible EU-wide verification of biofuel sustainability. Client Earth. 2013 Disponível em: https://www.clientearth.org/reports/131114-climate-and-forests-credible-verification-of-biofuel-sustainability.pdf. Acesso em: 5 jul. 2017.

OIT. Organização Internacional do Trabalho, 2016. Disponível em: <http://www.ilo.org/brasilia/lang--pt/ index.htm>. Acesso em: 16 ago. 2017.

ONU. Conferência das Nações Unidas sobre o Meio Ambiente e o Desenvolvimento. 1992. Disponível em: http://www.un.org/documents/ga/conf151/aconf15126-4.htm. Acesso em: 16 ago. 2017.

ONU. Relatório Brundtland, de 11 de dezembro de 1987. Report of the World Commission on Environment and Development. Disponível em: http://www.un.org/documents/ga/res/42/ares42-187.htm. Acesso em: 16 ago. 2017.

PALMUJOKI, Eero. Global principles for sustainable biofuel production and trade. International Environmental Agreements: Politics, Law and Economics, v. 9, n. 2, p. 135-151, 2009.

PAVLOVSKAIA, Evgenia. Sustainability criteria: their indicators, control, and monitoring (with examples from the biofuel sector). Environmental Sciences Europe Journal, v. 26, n. 14, 12 p., 2014. Disponível em: https://enveurope.springeropen.com/track/pdf/10.1186/s1230201400172? site=enveurope.springeropen. com. Acesso em: 02 ago.2017.

PAVLOVSKAIA. Using sustainability criteria in law. International Journal of Environmental Protection and Policy, n. 1 (4), p. 76-78, nov. 2013.

PELSY, Florent. The European Comission 2008 Directive Proposal on Biofuels: ACritique. Law, Environment and Development Journal. v.4, n.2. p. 119-134, 2008. 
O modelo meta-standard de implementação da sustentabilidade utilizado pela diretiva europeia...

TRENTINI, F.

POLS, A.J.K. The Rationality of Biofuel Certification: A Critical Examination of EU Biofuel Policy. Journal of Agricultural and Environmental Ethics, v. 28, n. 4, p. 667-681, 2015.

PONTE, Stefano. 'Roundtabling' sustainability: Lessons from the biofuel industry. Geoforum, n. 54, p. 261271, jul. 2014.

QUADRI, Susanna. L'evoluzione della Politica Energetica Comunitaria con particolare riferimento al settore dell'energia rinnovabile. Rivista Italiana di Diritto Pubblico Comunitario, v. 3-4, p. 839, 2011.

ROMPPANEN, Seita. The Role and Relevance of Private Actors in EU Biofuel Governance. Review of European Community \& International Environmental Law, v. 22, n. 3, p. 340-353, 2013.

SACHS, Ignacy. Caminhos para o desenvolvimento sustentável. Rio de Janeiro: Garamond, 2002.

SCARLAT, Nicolae; DALLEMAND, Jean-François. Recent developments of biofuels/bioenergy sustainability certification: a global overview. Energy Policy. v. 39, p. 1630-1646, 2011.

TRIBUNAL DE CONTAS EUROPEU. Relatório especial: O sistema da EU para a certificação de biocombustíveis sustentáveis. Luxemburgo: Serviço das publicações da União Europeia, 2016.

UE. Comissão Europeia. Report from the commission to the european parliament, the council, the european economic and social committee and the committee of the regions: renewable energy progress report. Bruxelas, 2013.

UE. Comissão Europeia. Report from the commission to the european parliament, the council, the european economic and social committee and the committee of the regions: renewable energy progress report. Bruxelas, 2015.

UE. Comissão Europeia. Proposta di Direttiva del Parlamento Europeo e del Consiglio sulla promozione dell'uso dell'energia da fonti rinnovabili. Bruxelas, 2008. Disponível em: http://www.parlamento.it/web/ docuorc2004.nsf/8fc228fe50daa42bc12576900058cada/a2d8c1d091b761bac12573e00033dd15/\$FILE/ COM2008 0019 IT.pdf. Acesso em: 16 ago. 2017.

UE. Comunicações oriundas das instituições, órgãos e organismos da União Europeia, 2010/C 160/01, de 16 de junho de 2010. Comunicação da Comissão sobre os regimes voluntários e os valores por defeito no regime de sustentabilidade da UE para os biocombustíveis e biolíquidos. Disponível em: http://eur-lex. europa.eu/legal-content/IT/TXT/?uri=uriserv:OJ.C .2010.160.01.0001.01.ITA\&toc=OJ:C:2010:160:TOC. Acesso em: 16 ago. 2017.

UE. Diretiva 2009/28/CE do Parlamento Europeu e do Conselho, de 23 de abril de 2009. Relativa à promoção da utilização de energia proveniente de fontes renováveis que altera e subsequentemente revoga as Directivas 2001/77/CE e 2003/30/CE. Estrasburgo, 2009a. Disponível em: http://eur-lex.europa.eu/legal-content/PT/TXT/?uri=CELEX:32009L0028. Acesso em: 16 ago. 2017.

UE. Diretiva 2009/30/CE do Parlamento Europeu e do Conselho, de 23 de abril de 2009. Por la que se modifica la Directiva 98/70/CE en relación con las especificaciones de la gasolina, el diésel y el gasóleo, se introduce un mecanismo para controlar y reducir las emisiones de gases de efecto invernadero, se modifica la Directiva 1999/32/CE del Consejo en relación con las especificaciones del combustible utilizado por los buques de navegación interior y se deroga la Directiva 93/12/CEE. Estrasburgo, 2009b. Disponível em: http://eur-lex.europa.eu/legal-content/PT/TXT/?uri=CELEX\%3A32009L0030. Acesso em: 16 ago. 2017.

UE. Livro Verde da Comissão, de 8 de março de 2006. Estratégia europeia para uma energia sustentável, competitiva e segura. Disponível em: http://eur-lex.europa.eu/legal-content/PT/TXT/?uri=LEGISSUM:127062. Acesso em: 16 ago. 2017.

USDA. EU Biofuels Annual 2016. Disponível em: https://gain.fas.usda.gov/Recent\%20GAIN\%20 Publications/Biofuels\%20Annual_The\%20Hague_EU-28_6-29-2016.pdf. Acesso em: 16 ago. 2016.

VALERA, Luca. La sostenibilità: un concetto da chiarire. Economia \& Diritto Agroalimentare, Firenze, v. 17, p. 39-53, 2012. 
WESTBERG, C. Johan; JOHNSON, Francis X. The Path Not Yet Taken: Bilateral Agreements to Promote Sustainable Biofuels under the EU Renewable Energy Directive. Estocolmo: Stockholm Environment Institute, 2013.

ZARILLI, Simonetta. Development of the emerging biofuels market In: Global governance. In: GOLDTHAU, Andreas; WITTE, Jan Martin. Global Energy Governance: The New Rules of the Game. Washington: Brookings Institution Press, 2010, p. 73-98.

Data de submissão do artigo: Abril de 2019

Data de aceite do artigo: Março de 2020(*)

\section{(*) NOTA TÉCNICA:}

Esclarecemos que, em razão do ataque de hackers a que foi submetido o conjunto de periódicos da Universidade Federal de Goiás (UFG), ao que se inclui a Revista da Faculdade de Direito da UFG (RFD/UFG), os artigos ordenados entre os números 21-30, referentes ao volume 43, embora tenham sido recebidos e aceitos em datas distintas e anteriores, dado o perecimento de suas referências, foram todos registrados com o expediente de aceite no mês de março de 2020. 